\title{
ANATOMIA DO LENHO DE ERYTHROXYLUM SUBSTRIATUM ${ }^{1}$
}

\author{
DIONE DAMBRÓS RADDATZ² PAULO FERNANDO DOS SANTOS MACHADO ${ }^{3}$ ROSSANA

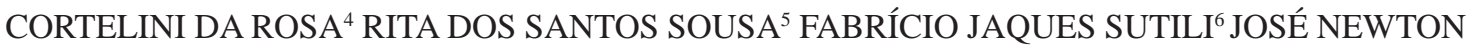 \\ CARDOSO MARCHIORI ${ }^{7}$
}

\begin{abstract}
RESUMO
O lenho de Erythroxylum substriatum (Erytroxylaceae) é anatomicamente descrito e ilustrado com fotomicrografias. Na estrutura anatômica, salientam-se: porosidade difusa; vasos numerosos, solitários e em múltiplos radiais; parênquima tanto paratraqueal como apotraqueal; raios estreitos, numerosos, heterogêneos; e fibras com pequenas pontoações indistintamente areoladas.

Palavras-chave: Anatomia da madeira, Erytroxylaceae, Erythroxylum substriatum, Recuperação de áreas degradadas, Reófitas.
\end{abstract}

\begin{abstract}
[Anatomy of the wood of Erythroxylum substriatum].

The wood of Erythroxylum substriatum (Erythroxylaceae) is anatomically described and illustrated with photomicrographs. The following features stand out in the anatomical structure: diffuse porosity; numerous vessels, solitary and in radial multiples; axial parenchyma both apotracheal and paratracheal; fine, abundant and decidedly heterogeneous rays; and wood fibers with small indistinctly bordered pits.
\end{abstract}

Key words: Ecological Restoration, Erythroxylaceae, Erythroxylum substriatum, Rheophytes, Wood Anatomy.

1 Recebido em 13-III-2018 e aceito para publicação em 05-IV-2018.

2 Engenheiro Florestal, mestrando do Programa de PósGraduação em Engenharia Florestal, Universidade Federal de Santa Maria. Santa Maria, RS, Brasil. dionedambros@hotmail.com

3 Engenheiro Florestal, doutorando do Programa de PósGraduação em Engenharia Florestal, Universidade Federal de Santa Maria. Santa Maria, RS, Brasil. barcasole@gmail.com

4 Engenheira Florestal, mestranda do Programa de PósGraduação em Engenharia Florestal, Universidade Federal de Santa Maria. Santa Maria, RS, Brasil. ro.cortelini@hotmail.com

5 Engenheira Biofísica, doutoranda do Programa de PósGraduação em Engenharia Florestal, Universidade Federal de Santa Maria. Santa Maria, RS, Brasil. ritasousa.ufsm@gmail.com

6 Engenheiro Florestal, Dr., Professor Adjunto do Departamento de Ciências Florestais, Universidade Federal de Santa Maria.Fjsutili@gmail.com

7 Engenheiro Florestal, Dr., Professor Titular do Departamento de Ciências Florestais, Universidade Federal de Santa Maria. Santa Maria, RS, Brasil. marchioricfl@gmail.com

\section{INTRODUÇÃO}

Endêmica do Bioma Mata Atlântica, no Rio Grande do Sul, Erythroxylum substriatum O. E. Schulz. é planta reófila e integrante da "Lista Oficial das Espécies da Flora Brasileira Ameaçadas de Extinção", do Ministério do Meio Ambiente (MMA, 2008), fato que acresce importância à realização de estudos sobre a anatomia de seu lenho. As coletas disponíveis em herbários indicam que a mesma distribui-se no centro do Estado, Campanha e Litoral Sul.

Pesquisas recentes sobre propriedades biotécnicas de Erythroxylum substriatum, realizadas no Laboratório de Engenharia Natural (LaBEN) da Universidade Federal de Santa Maria, mostraram índice de sobrevivência em propagação vegetativa superior a $70 \%$, considerado satisfatório segundo Sauli, Cornelini \& Pretti (2003) e Schiechtl (1973). 
O presente trabalho visa a descrever e ilustrar com fotografias a anatomia microscópica do lenho de Erythroxylum substriatum, bem como discutir sua estrutura à luz da escassa literatura sobre esse gênero botânico.

\section{REVISÃO DE LITERATURA}

A família Erythroxylaceae compreende quatro gêneros, salientando-se Erythroxylum P. Browne, que reúne 250 espécies, distribuídas pelas regiões tropicais e subtropicais do mundo (Amaral Jr, 1980). No Brasil encontram-se 123 espécies nativas, 55\% das quais na Mata Atlântica (Costa-Lima \& Alves, 2015). O interesse farmacológico pelo gênero remonta ao século XIX, com o início dos estudos sobre Erythroxylum coca, espécie de uso secular na região andina da América do Sul (Zuanazzi et al., 2001).

Arbusto ou arvoreta (Figura 1A, B) de até três metros de altura, Erythroxlum substriatum apresenta folhas elípticas, oblongas ou ovadooblongas $(3-5 \mathrm{~cm} \times 1,9-2,2 \mathrm{~cm})$ de ápice obtuso, emarginado ou mucronulado, base largo-aguda ou obtusa (Figura 1C, D) e com 22-36 nervuras no limbo, visíveis em ambas as faces (Sobral, 1987); as estípulas, de 2,4 a 3,2 mm de comprimento, apresentam estrias longitudinais. As flores, com pedicelos de 3,5 a 7,0 mm (Figura 1C, D), têm cálice de $1,7 \mathrm{~mm}$ de comprimento e pétalas de 3,2mm de comprimento por 1,5mm de largura (Sobral, 1987).

Sobre a anatomia da madeira, Metcalfe \& Chalk (1972) referem para o gênero Erythroxylum: vasos pequenos $(50-100 \mu \mathrm{m})$, solitários e em múltiplos; placas de perfuração simples; pontoações intervasculares alternas, muito pequenas; pontoações raio-vasculares e parênquimo-vasculares frequentemente alongadas e quase simples; elementos vasculares de 0,4-0,8 mm de comprimento; parênquima axial variável e difícil de classificar, sugerindo um tipo intermediário entre apotraqueal e paratraqueal; séries parenquimáticas com 6-8 células e cristais usualmente abundantes, em câmaras; raios com 2-5 células de largura, menos de $1 \mathrm{~mm}$ de altura e decididamente heterogêneos, com 6-8 fileiras marginais de células quadradas e eretas nos multisseriados; e fibras com pontoações areoladas, por vezes com bordas muito pequenas.

Sobre o mesmo tema, Record \& Hess (1943) relacionam: poros pequenos a diminutos, muito numerosos; vasos com placas de perfuração simples, sem espessamentos espiralados e com pontoações pequenas, em arranjo alterno; raios com 1 ou 2 (até 3 ) células de largura, até 40 células de altura (geralmente até 25) e claramente heterogêneos; pontoações para com células de parênquima semelhantes às intervasculares, ou grandes e irregulares; e fibras com pontoações indistintamente areoladas.

\section{MATERIAL E MÉTODOS}

O material em estudo compreende duas amostras de madeira e material botânico, coletados na Fundação Zoobotânica do Rio Grande do Sul (Porto Alegre) e anexados ao Herbário SMDB com os números 17.525 e 17.526 (Figura 1E, F).

Do material lenhoso foram extraídos três cubos de lenho com 30mm de lado, orientados para a obtenção de cortes anatômicos nos planos transversal, longitudinal radial e longitudinal tangencial; de outro fragmento lenhoso foram obtidos finos palitos, com vistas ao preparo de lâminas de macerado.

Os corpos-de-prova foram fervidos em água, até a retirada completa do ar, e seccionados em micrótomo de deslize, no Laboratório de Anatomia da Madeira da Universidade Federal de Santa Maria. Os cortes anatômicos foram coloridos com Safrablau e montados em lâminas permanentes, com Entellan (Burger \& Richter, 1991). No preparo de lâminas de macerado usou-se Jeffrey (Freund, 1970) e coloração da pasta de fibras com safranina.

A descrição qualitativa do lenho seguiu as recomendações do IAWA Committee (Wheeler et al., 1989). Para a determinação da percentagem dos tecidos, bem como da altura e largura de raios (inclusive de seu corpo e margens) em 

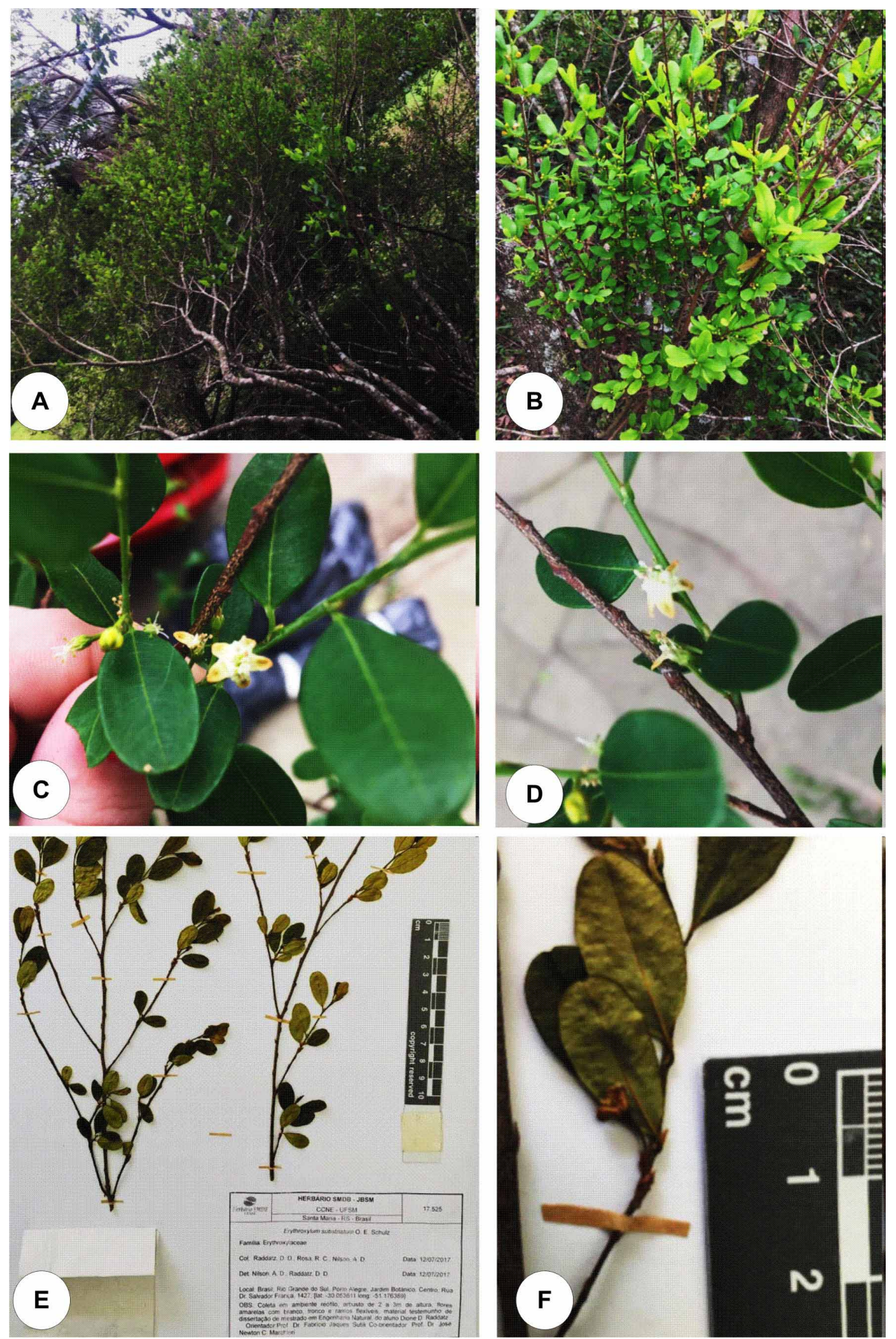

FIGURA 1: Erythroxylum substriatum. A - Aspecto geral de um indivíduo adulto. B - Ramos jovens, em detalhe. C,D - Flores, folhas e ramos, em destaque. E, F - Exsicata, com detalhes. 
número de células, usou-se um contador de laboratório, conforme preconizado por Marchiori (1980), realizando-se 600 determinações ao acaso. A frequência de poros foi obtida a partir de um quadrado de área conhecida, superposto a fotomicrografias em diferentes pontos da seção transversal.

Os caracteres anatômicos foram medidos com ocular de escala graduada em microscópio binocular Carl Zeiss, no Laboratório de Anatomia da Madeira do Departamento de Ciências Florestais da Universidade Federal de Santa Maria (UFSM).

As imagens que ilustram o texto foram tiradas em fotomicroscópio Leica, modelo DM 2000, munido com câmera digital Leica (modelo DFC 295), no Laboratório de Botânica Estrutural do Departamento de Biologia, no Centro de Ciências Naturais e Exatas da UFSM.

\section{DESCRIÇÃO MICROSCÓPICA}

Anéis de crescimento: distintos, marcados por parênquima marginal e maior lignificação de fibras no lenho tardio.

Vasos: extremamente numerosos $(253 \pm 54$ $\left.(177-368) / \mathrm{mm}^{2}\right)$, solitários, menos comumente em múltiplos radiais de 2-5, compondo $27 \pm 6$ $\%$ do volume da madeira. Porosidade difusa (Figura 2A). Poros de $33 \pm 4,7(25-44) \mu \mathrm{m}$ de diâmetro, de contorno poligonal e paredes finas $(2,7 \pm 0,7(1,9-3,8) \mu \mathrm{m})$ (Figura 2B). Elementos vasculares de comprimento médio (442 \pm $106(280-670) \mu \mathrm{m})$, com placas de perfuração simples, oblíquas, e apêndices curtos $(65 \pm 43$ $(20-230) \mu \mathrm{m})$, geralmente em uma das extremidades. Pontoações intervasculares pequenas e arredondadas $(4,9 \pm 0,3(4,6-5,2) \mu \mathrm{m})$, em arranjo alterno. Pontoações raio-vasculares e parênquimo-vasculares alargadas, aparentemente simples.

Parênquima axial: ocupando $9 \pm 3,5 \%$ do volume da madeira e em arranjo de difícil definição, variando desde aliforme confluente, aliforme e vasicêntrico incompleto, até apotraqueal difuso, difuso-em-agregados e em faixa marginal, no limite do anel de crescimento
(Figura 2A-B). Conteúdos, ausentes. Séries parenquimáticas de $395 \pm 78(225-613) \mu \mathrm{m}$ de altura, com $3-7$ células. Cristais romboédricos, em séries cristalíferas visíveis, inclusive em seção transversal.

Raios: muito numerosos $(24 \pm 4,5(18-33)$ raios/mm), ocupando $19 \pm 4,2 \%$ do volume da madeira; estreitos $(22 \pm 5(15-33) \mu \mathrm{m})$ e heterogêneos, compostos de células procumbentes, quadradas e eretas (Figura 2C).Os multisseriados, principalmente bisseriados $(56 \%)$, menos comumente, trisseriados (18\%); de 193 $\pm 142(10-620) \mu \mathrm{m}$ e $1-13$ células de altura, com margens de $87 \pm 71(10-300) \mu \mathrm{m}$ e $1-22$ células de altura. Os unisseriados (26\%), de 373 $\pm 233(150-1000) \mu \mathrm{m}$, com $3-27$ células de altura. Células radiais de contorno arredondado ou oval, em plano tangencial (Figura 2F); células envolventes, células radiais de paredes disjuntas e células perfuradas, ausentes. Raios fusionados e conteúdos, presentes.

Fibras: fibrotraqueóides muito lignificados (não gelatinosos), de comprimento médio (886 $\pm 186(500-1300) \mu \mathrm{m})$, com $13 \pm 2,2(8-18)$ $\mu \mathrm{m}$ de largura e de paredes espessas $(4,9 \pm 1,1$ $(2,5-7) \mu \mathrm{m})$, ocupando $45 \pm 7,8 \%$ do volume da madeira (Figura 2B, F). Espessamentos espiralados, fibras septadas e traqueídeos, ausentes.

Outros caracteres: variantes cambiais, tubos laticíferos e taniníferos, canais intercelulares, células oleíferas, células mucilaginosas, estratificação e máculas medulares, ausentes.

\section{DISCUSSÃO}

O lenho de Erythroxylum substriatum concorda, integralmente, com as referências feitas ao gênero, por Record \& Hess (1943) e Metcalfe \& Chalk (1972), salientando-se: porosidade difusa, vasos numerosos, solitários e em múltiplos radiais de poucas unidades; pontoações intervasculares pequenas e alternas; parênquima axial em padrões tanto paratraqueal como apotraqueal; raios heterogêneos, com 1-3 células de largura; e fibras com pequenas pontoações areoladas. 

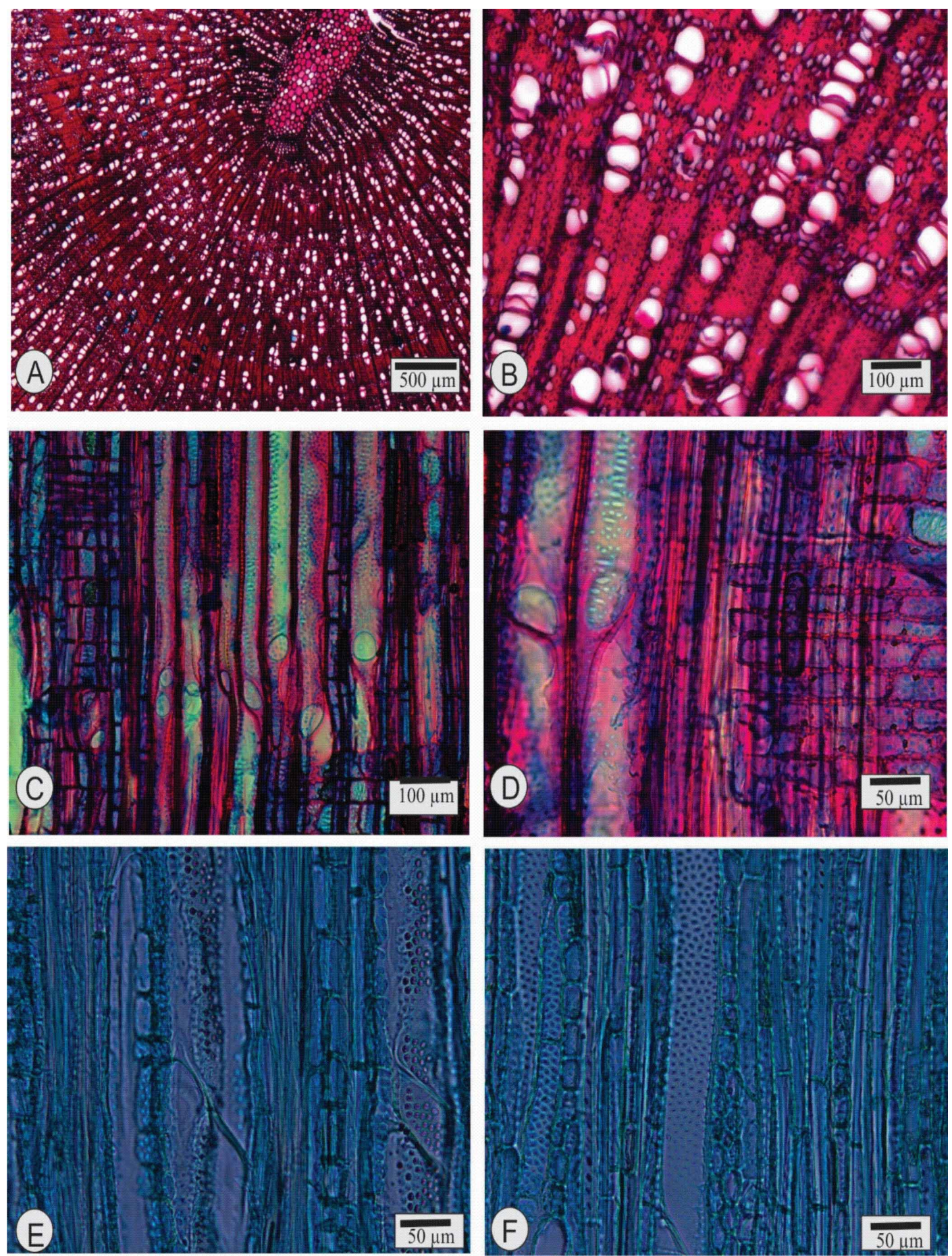

FIGURA 2. Detalhes anatômicos do lenho de Erythroxylum substriatum. A-Medula e xilema secundário com porosidade difusa (seção transversal). B - Poros solitários e em múltiplos radiais, parênquima axial e fibras de paredes espessas (seção transversal). C - Placas de perfuração simples e células quadradas de raio, em seção longitudinal radial. D - Placas de perfuração simples e raios de células quadradas e eretas (seção longitudinal radial). E, F - Aspectos do lenho em seção longitudinal tangencial, destacando pontoações intervasculares, raios e fibras. 
Pequenas diferenças, entretanto, se observam em caracteres quantitativos, salientando-se o menor diâmetro de vasos no material em estudo (25-40 $\mu \mathrm{m}$ vs. 50-100 $\mu \mathrm{m}$, segundo Metcalfe \& Chalk, 1972), bem como fibras mais curtas (500$1300 \mu \mathrm{m}$ vs. $1100-2800 \mu \mathrm{m})$. Estas diferenças podem ser atribuídas tanto à espécie botânica, como ao caráter juvenil do lenho examinado (observar a presença de medula na Figura 2A) ou, até mesmo, a mecanismo adaptativo à reofilia.

Presumivelmente reófila, por sua ocorrência na vegetação do fundo do vale do rio das Antas, juntamente com Aspidosperma riedelii, Callisthene inundata, Lafoensia nummulariifolia e outras espécies capazes de resistir à velocidade da correnteza da água por ocasião das enchentes, o material em estudo, mesmo assim, não exibe a síndrome anatômica de reofilia descrita, inicialmente, por Denardi (2007), até mesmo pelo fato da material investigado ser procedente de exemplares cultivados no Jardim Botânico de Porto Alegre.

Vasos muito estreitos e de paredes finas são invariavelmente constantes em espécies reófilas e se justificam pela flexibilidade conferida ao lenho; a ausência de fibras gelatinosas, todavia, basta para excluir a espécie deste grupo de plantas. A atribuição de reofilia ao lenho de Erythroxylum substriatum, em outras palavras, requer o exame de material coletado diretamente na natureza.

\section{AGRADECIMENTOS}

Os autores agradecem à Fundação Zoobotânica do Estado do Rio Grande do Sul (FZB/RS) e, em especial, ao amigo Ari Nilson, pelo material botânico e lenhoso fornecido ao presente estudo.

\section{REFERÊNCIAS BIBLIOGRÁFICAS}

AMARAL JUNIOR, A. Erythroxylaceae. In: REITZ,

R. (ed.). Flora Ilustrada Catarinense. Itajaí: Herbário Barbosa Rodrigues, 1980. 64p.
BURGER , L.M.; RICHTER, H.G. Anatomia da Madeira. São Paulo: Ed. Nobel, 1991. 154 p.

COSTA-LIMA, J. L.; ALVES, M. Flora da Usina São José, Igarassu, Pernambuco: Erythroxylaceae. Rodriguésia, v. 66, n. 1, p. 11, 2015.

DENARDI, L. Anatomia e flexibilidade do caule de quatro espécies lenhosas para o manejo biotécnico de cursos de água. 2007. 113 f. Tese (Doutorado em Manejo Florestal) - Universidade Federal de Santa Maria, Santa Maria, 2007.

FREUND, H. Handbuch der Mikroskopie in der Technik. Frankfurt: Umsham Verlag, 1970. 375 p.

MARCHIORI, J.N.C. Estudo anatômico do xilema secundário de algumas espécies dos gêneros Acacia e Mimosa, nativas no estado do Rio Grande do Sul. 1980. 186 f. Dissertação (Mestrado em Engenharia Florestal) - Universidade Federal do Paraná, Curitiba, 1980.

METCALFE, C.R.; CHALK, L. Anatomy of the Dicotyledons. Oxford: Clarendon Press, 1972. p. 274-275.

MMA - Ministério do Meio Ambiente. Instrução Normativa. Brasília, setembro de 2008 (disponível no site do MMA).

RECORD, S.J.; HESS, R.W. Timbers of the New World. New Haven: Yale University Press, 1943. p. 146-150.

SAULI, G.; CORNELINI, P.; PRETI, F. Manuale d' Ingegnaria Naturalistica Applicabile ai Settori delle Strade, Cave, Discariche e Coste Sabbiose. Roma: Regione Lazio, 2003.

SCHIECHTL, H. Bioingegneria Forestale basimateriali da construzioni vivi - metodi. Itália: Edizione Castaldi-Feltre, 1973.

SOBRAL, M.. Erythroxylum (Erythroxylaceae) do Rio Grande do Sul, Brasil. Pesquisas. Série Botânica, São Leopoldo, v. 38, p. 7-42, 1987.

ZUANAZZI, J.A.S.; TREMEA, V.; LIMBERGER, R.P.; SOBRAL, M.; HENRIQUES, A.T. Alkaloids of Erythroxylum (Erythroxylaceae) species from Southern Brazil. Biochemical Systematics and Ecology, n. 29, p. 819-825, 2001.

WHEELER, E.A.; BAAS, P.; GASSON, P.E. IAWA list of microscopic features for hardwood identification. IAWA Bulletin, v. 10, n. 3, p. 218359, 1989. 